\title{
Leaf Temperatures in a Gas Exchange Chamber and in the Open Air
}

\author{
B. SEIBERT, ${ }^{1}$ W. KOCH \\ Forstbotanisches Institut der Universität München, Amalienstr. 52, \\ D 8000 München 40, Federal Republic of Germany
}

AND B. M. ELLER

Institut für Pflanzenbiologie der Universität Zürich, Zollikerstr. 107, CH 8008 Zürich, Switzerland

Received 19 February 1979

\begin{abstract}
Leaf temperatures in a Koch fully climatized gas-exchange chamber as designed by Siemens and in a similarly equipped open-air reference were measured with horizontally and vertically inserted thermocouples on Nerium oleander L. On a sunny day with only little air movement and an average air temperature of $20.4{ }^{\circ} \mathrm{C}$, leaf over-temperatures in the gas-exchange chamber were lower on average by $2.2 \mathrm{~K}$. The extent of reduction of over-temperature in the chamber is determined by the reduced global radiation in the chamber and the differences of wind velocities in chamber and reference. Differences in the ventilation intensity in the chamber have no demonstrable influence on the leaf over-temperatures. The over-temperatures of the reference leaves, on the other hand, depend to a large degree on air velocity. The changed radiation and air flow conditions in the chamber as compared with open-air conditions have consequences for the physiological reactions of the enclosed plant and must be taken into account when comparing results from gas-exchange measurements with open-air conditions. For further improvements of gas-exchange measurement equipment, air flow conditions and radiation quantity and quality might be starting points
\end{abstract}

\section{INTRODUCTION}

For more than 70 years, gas-xchange chambers have been in use for the investigation of the budget of $\mathrm{CO}_{2}$ and water vapour of plants. The common principle is the closing of the air stream between the object of measurement, i.e. the plant or a part of it, and the measuring instruments used. The closed air stream renders the exact quantitative recording of the plant gas-exchange possible, but requires enclosure of the photosynthetically active parts of plants during measurement.

The material used for enclosing, usually glass or plastic material, produces changes of climate in contrast to that of the natural habitat outside, due mainly to its low degree of transmission of long-wave radiation (Eller and Koch, 1977). The

\footnotetext{
${ }^{1}$ Present address: Institut für Pflanzenbiologie der Universität Zürich, Zollikerstr. 107, CH 8008 Zürich, Switzerland.
} 
thermal re-radiation from the material of the chamber and of the enclosed plant parts remains in the system and causes overheating if there is no air-conditioning system. The reduced mass interchange in unconditioned chambers causes additional overheating, and even on days of low radiation intensities the plant organs are heat-stressed. As an example, the widely known and often described 'midday depression of assimilation' (see Bosian, 1955) is, as demonstrated by Bosian (1933, 1960), mostly an effect of overheating in the cuvette.

Whenever the object of ecophysiological reaearch is the study of plant responses to the environmental conditions of the habitat, the altered conditions in the climate inside the chamber cannot be tolerated. A first attempt to solve this problem is a fully climatized cuvette. A survey of the methods used today can be found in Jarvis and Catský $(1971 a, b)$, Jarvis, Catsky, Eckardt, Koch, and Koller (1971a), and Jarvis, Eckardt, Koch, and Catský (1971b). The automatic control of air temperature, humidity, and $\mathrm{CO}_{2}$ concentration inside the chamber does not cause any serious difficulties; but any chamber construction still gives rise to considerable modifications of the radiation climate and the convection conditions around the enclosed plant (Koch, Lange, and Schulze, 1971). The absorption of incident radiation by the cuvette material used in this study deprives the chamber climate and the enclosed plant of $20 \%$ of global radiation and $9 \%$ of the photosynthetically active incident radiation (Eller and Koch, 1977; Koch and Eller, 1977). The necessary heat interchange between the cooling elements of the chamber system and the overheated air requires a ventilation that reduces the possibilities of a climate regulation conforming to open-air conditions and renders measurements under free convection impossible.

There are as yet only a few pointers regarding the physiological importance of the above-mentioned climate changes occurring even in fully climatized chambers (e.g. Koch et al., 1971). In any case, some errors in the measurements must be taken into consideration. Above all the ultraviolet radiation below a wavelength of $400 \mathrm{~nm}$, almost completely absorbed by Plexiglas (Eller and Koch, 1977), figures prominently in the growth behaviour of plants (Pisek, 1960; Bogenrieder and Klein, 1977). Moreover, owing to the loss of global radiation, a quantitative change of the mass and energy exchange occurs.

The leaf temperature is most suitable for investigations on plant responses to the changed climate in gas-exchange chambers. Unlike transpiration and net assimilation, it can be measured in the same way inside and outside the chamber, and comparisons are easy. The leaf temperature is an expression of and a determining factor for the energy exchange between the leaf and its environment. It is a sensitive indicator of the energy flux conditions and is strongly correlated with the physiological reactions in the plant organs (Gates, 1965). The most important component of energy input into the leaf blade is (Casperson, 1957) radiation of various wavelengths and sources. One of the major components of energy output is the heat flux to the air (Loomis, 1965), which is mainly determined by the convection conditions and therefore by the air flow around the leaf (Gates, 1964). The convection conditions also influence the latent heat output in the form of transpiration (Avery, 1967). On the one hand, the removal of air saturated with 
water-vapour from the leaf boundary layer raises transpiration; on the other hand, forced convection causes closing of the stomata (Stälfelt, 1960b) and reduces transpiration in this way.

\section{MATERIALS AND METHODS}

\section{Plant material}

Two potted plants of Nerium oleander L. of about the same size, watered daily to avoid water stress, were used for our experiments. The pots were placed on the supports of the gas-exchange chamber and of the reference.

\section{Disposition of the chamber}

The leaves to be measured were fixed with nylon threads to avoid any tearing out of the temperature sensors when leaves are exposed to wind. Such fixing does not influence the boundary layer around the leaves (Parlange, Waggoner, and Heichel, 1971; Parlange and Waggoner, 1972), and their influence on leaf temperatures can be neglected. Nerium has advantages for leaf temperature measurements. It has relatively thick and solid leaves which allow the insertion of the thin temperature sensors. The smooth edge of the leaves avoids any complicated boundary layer conditions, and comparisons require only measurements at corresponding points of the different leaves. The temperature measurement of leaves in the cuvette and in the open were carried out on the field measurement equipment described by Eller and Koch (1977). In this equipment, a Koch gas-exchange chamber as designed by Siemens (Koch, Klein, and Walz, 1968) is installed on a support $1.50 \mathrm{~m}$ above ground level. For the reference, a second support is installed nearby mounted with installations that differ from those of the chamber only in omission of the Plexiglas walls and the climatization. Air ventilator, solarimeter, and leaf fixation correspond to those in the chamber.

\section{The gas-exchange chamber}

The Koch gas-exchange chamber guarantees a largely smooth-running experiment from the technical point of view by reason of several years' experience in short-term and long-term measurements under laboratory and open-air conditions (Benecke, 1976; Bogenrieder and Klein, 1977; Caldwell, 1972; Lange and Schulze, 1971; Lange, Schulze, Evenari, Kappen, and Buschbom, 1974, 1975; Schulze, 1970; Schulze and Koch, 1971; Schulze, Lange, and Koch 1972a,b; Schwarz, 1969, 1971). For the methods of full climatization see Koch et al. (1968).

The supports of the chamber as well as of the reference were horizontally oriented in a north-south direction, according to the recommendations given by Eller and Koch (1977).

\section{Measurement of temperature}

Lacquered copper and constantan wires (Schildbach, K.G., Eckenhagen) with a diameter of $0.05 \mathrm{~mm}$ were used for the thermocouples, which were made by the method of Eller (1971). It is very difficult to make thermocouples with wire dimensions smaller than $0.05 \mathrm{~mm}$, and the insertion of such fragile wires is almost impossible. On the other hand, the radiation errors occurring with wire dimensions of $0.05 \mathrm{~mm}$ are so small (Duchon, 1964) that they may be neglected, since the comparison of the values in chamber and reference compensates for most errors.

Eller (1971) demonstrated that two thermocouples (we use the expression 'thermocouple' for the hot junction of a thermocouple), one crossing the isotherms around the leaf vertically, the other at as small as possible an angle to the leaf surface, determine the range in which the real leaf temperature lies. According to this method, in our measurements one thermocouple was inserted carefully flat under the epidermis; the remaining part thus lay flat on the leaf above the epidermis. For the vertical insertion, on the upper side of the leaf just as the horizontal one, three thermocouples were used in chamber and reference, since a vertically inserted thermocouple is far more prone to drop out by mechanical stress than a horizontally inserted one.

At the insertion point was a wound reaction. Secreted cell sap dried, and a callus tissue enclosed the thermojunction and guaranteed good contact between soldering point and leaf tissue. The thermocouples did not drop out of the leaf even when the wind blew strongly. The influence of the callus tissue formed (Eller 1971) on the leaf temperature can be neglected for comparisons between chamber and reference measurements. The insertion method is quite reproducible, and the wound reactions of leaves in chamber and reference are analogous. 
Special care was taken to insert the thermocouples in corresponding sections of the leaf, the vertical and horizontal ones as well as those on chamber and reference leaves. The insertion points were about $10 \mathrm{~mm}$ away from the lateral edge of the leaf in the mid-leaf region.

The air temperature used for the comparison was measured with identically made thermocouples $20 \mathrm{~mm}$ above the leaf. At this distance, the temperature field around the leaf is reduced about 90\% (Berger-Landefeldt, 1958). The use of identically made thermocouples and the measurement above the leaf compensates for potential radiation errors.

The temperature of the reference bath was fixed at $19.00^{\circ} \mathrm{C}$ to have small temperature differences between cold and hot junction and a high resolution. Amplifier, switch, and analogue registration were as described in Eller (1971), the digital registration as in Eller and Koch (1976).

The measurements were carried out on selected days in September 1977 between 0900 and 1600 .

\section{Analysis of the measurements}

The evaluation of the punched tapes and the conversion of the values into physical ones were carried out at the Computation Centre of the University of Zurich with the computer software as described in Eller and Koch (1976). The calculation of the temperatures measured with the copper-constantan thermocouples is based on a thermotension of $41 \mu \mathrm{V} \mathrm{K}^{-1}$. The further treatment of the leaf temperature data was carried out at the Computation Centre of the Bayerisches Ministerium für Ernährung, Landwirtschaft und Forsten on an IBM 370. Three Fortran IV programmes were written, and the data were analysed in three steps.

First, the measurements of the vertically inserted thermocouples $\left(\operatorname{LTV}_{1 i}\right.$ to $\mathrm{LTV}_{3 i} ; i=1 \ldots n$ the scan-number) were evaluated with a histogram of the SPSS (Standard Package for the Social Sciences). The deviations of the single thermocouple from the mean value of the three thermocouples used were calculated for each minute scan and averaged for the day according to:

$$
C_{1}=\frac{1}{n} \sum_{i=1}^{n} \sum_{j=1}^{3} \mathrm{LTV}_{t}-\frac{1}{n} \sum_{i=1}^{n} \mathrm{LTV}_{1 i}
$$

and analogously for $C_{2}$ and $C_{3}$. The systematic error $\left(C_{j} ; j=1,2,3\right)$ of the single thermocouple values was taken into account for the further evaluation.

In the second programme, leaf temperature, difference between the temperatures measured with vertical and horizontal insertion respectively, and the difference between the temperatures of leaf and air (the latter also measured with thermocouples) were calculated for chamber and reference. The systematic errors $C_{j}$, calculated in equation 1 , were taken into consideration when computing the mean of the vertically inserted thermocouples. The temperature value of each thermocouple $\mathrm{LTV}_{\|}$was corrected by its systematic error $C_{j}$. Then the deviation $\Delta Y_{j}$ of this corrected value from the average temperature $L T V$, taken at time-steps of one minute (i) was examined according to :

$$
\Delta T_{j}=\overline{\mathrm{LTV}}_{l}-\left(\mathrm{LTV}_{j}+C_{j}\right) \quad(j=1,2,3)
$$

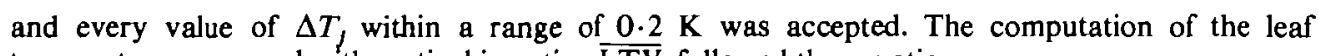
temperature measured with vertical insertion $\overline{\mathrm{LTV}}$, followed the equation:

$$
\overline{\mathbf{L T V}}_{l}=\frac{1}{3} \sum_{j=1}^{3}\left(\mathrm{LTV}_{J}+C_{j}\right)
$$

where $i$ is the scan number. The correction of the values $C_{f}$ is cancelled by the condition:

$$
\sum_{j=1}^{3} C_{j}=0
$$

and therefore served only to include the maximum of the distribution curve when checking the 'validity' of the single values. The arithmetical mean of the value of the horizontally inserted thermocouple (LTH) and the calculated value $\overline{\mathrm{LTV}}$, of those inserted vertically was defined, more or less arbitrarily (Eller, 1971), as leaf temperature for the comparison:

$$
\mathrm{LT}_{l}=\frac{1}{2}\left(\mathrm{LTH}_{1}+\overline{\mathrm{LTV}}_{i}\right)
$$

The third programme served for the securing of the pointers resulting from the evaluation above. The most unfavourable case was assumed (Eller, 1971) in which the real leaf temperature lies at the upper and lower end respectively of the temperature range measured with the vertical and 
horizontally inserted thermocouples. Generally, the vertically inserted thermocouples, with the over-temperatures occurring during the day-time, show lower temperature values than the horizontally inserted ones. So the lowest over-temperature value recorded with vertical insertion was taken; this temperature value and the one measured with vertical insertion determine a temperature range that was plotted and calculated. The overlapping percentage of the temperature ranges of chamber and reference systems served to check the results from programme 2.

The regression lines for the description of the dependence between global radiation and leaf over-temperature were calculated with the programmes STAT 1-05A and STAT 1-22A on a HP-65 calculator. The regression lines are adapted by the method of least squares.

\section{RESULTS}

With an average air temperature of $20.4^{\circ} \mathrm{C}$, the mean over-temperature of a leaf in the chamber is $1.6 \mathrm{~K}$ and that of a reference leaf $3.8 \mathrm{~K}$. The measurement in the chamber was carried out with the normal, almost turbulent air flow of the cooling system of about $1.8 \mathrm{~m} \mathrm{~s}^{-1}$; that in the reference under almost free convection, with little air movement. Figures 1 and 2 show the over-temperature of a reference leaf to be much more dependent on the quantity of incident radiation than that of a leaf

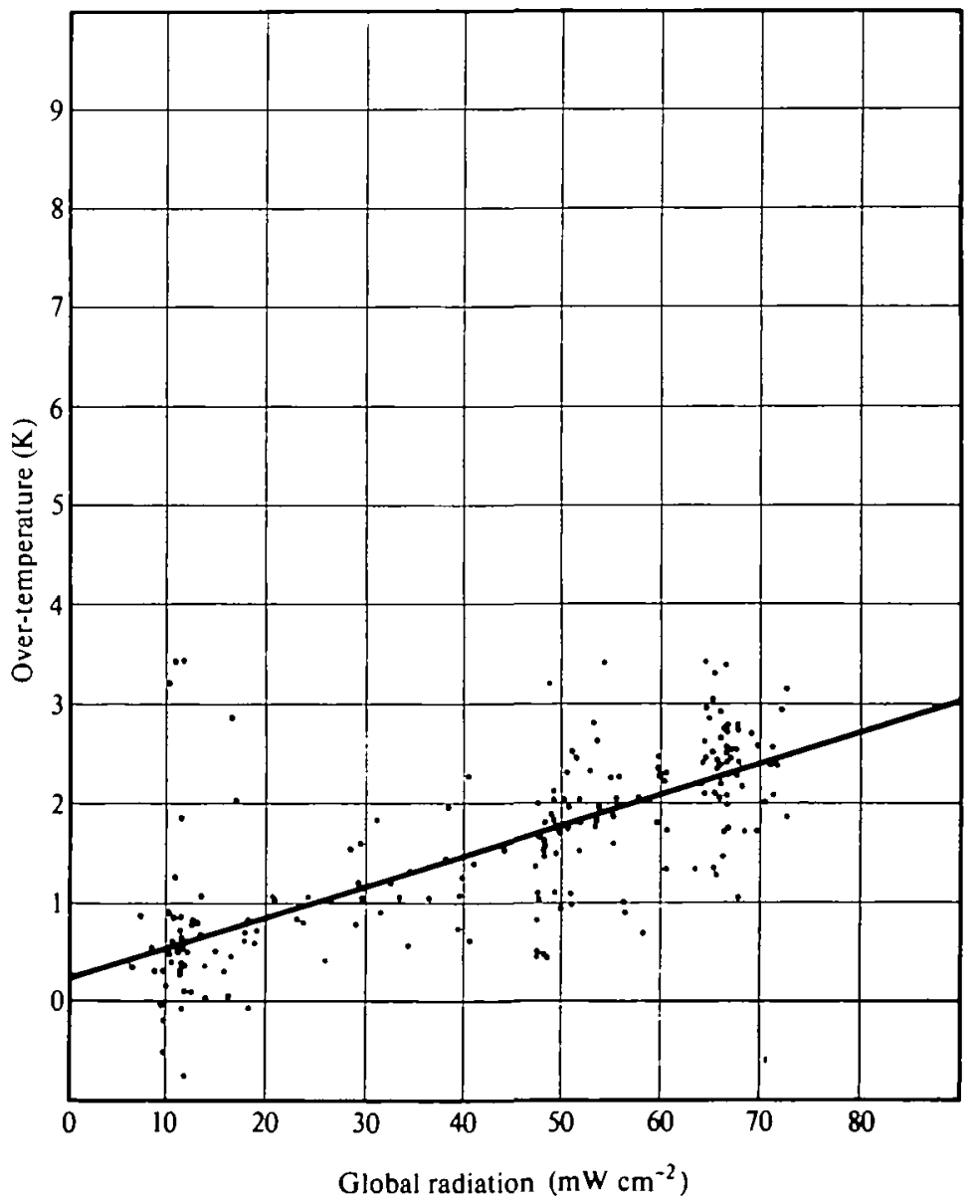

FIG. 1. Global radiation ( $\mathrm{mW} \mathrm{cm}^{-2}$ ) and over-temperature $(\mathrm{K})$ of Nerlum oleander $\mathrm{L}$. in the gas-exchange chamber with an air velocity of about $1.8 \mathrm{~m} \mathrm{~s}^{-1}$. Regression line: $\mathrm{OT}=0.22+$ $0.31 \mathrm{GR}(\mathrm{K}) ; r^{2}=0.53$. 


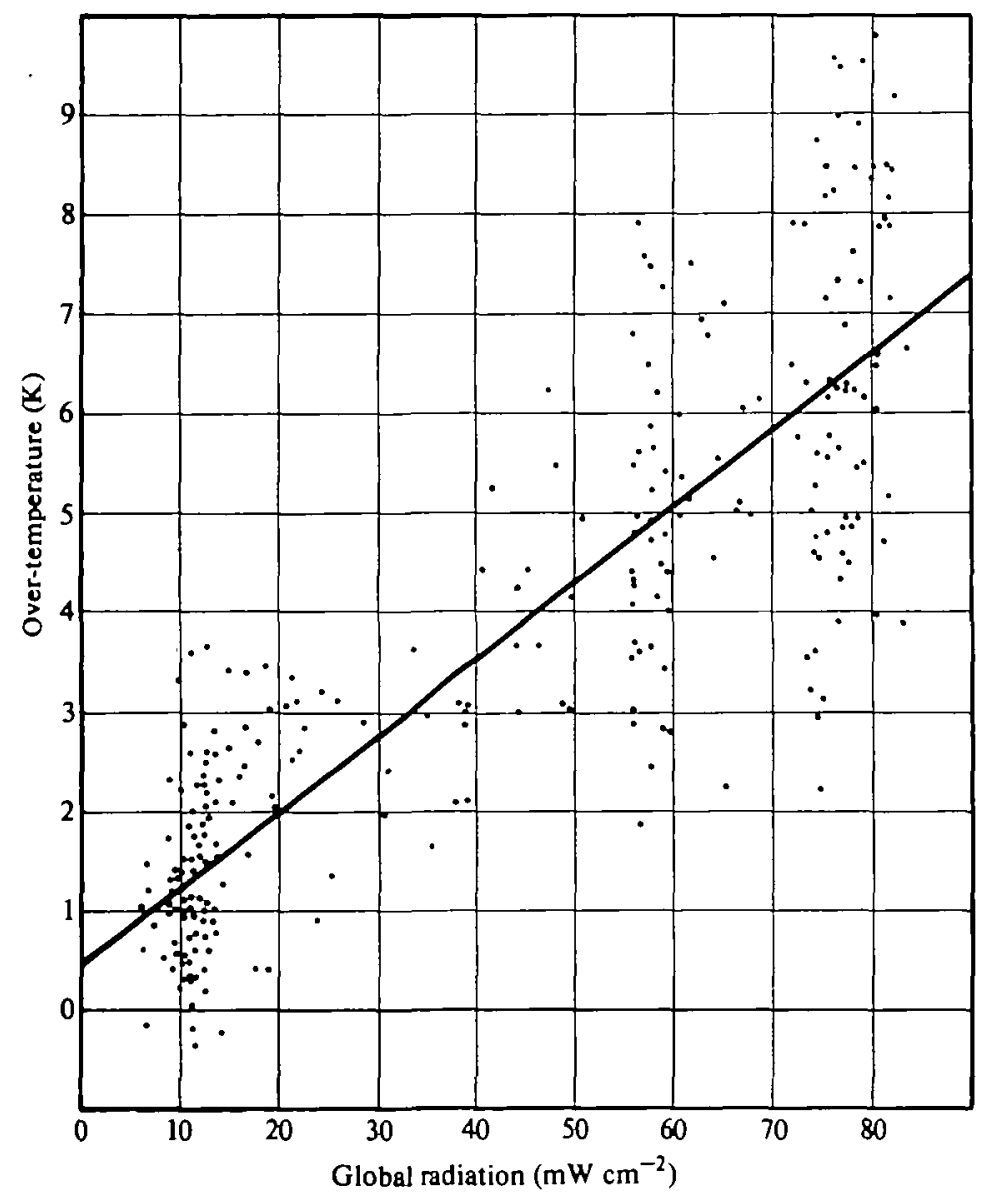

FIG. 2. Global radiation ( $\mathrm{mW} \mathrm{cm}^{-2}$ ) and over-temperature $(\mathrm{K})$ of Nerium oleander $\mathrm{L}$. on the reference with only little air movement. Regression line. OT $=0.42+0.077 \mathrm{GR}(\mathrm{K}) ; r^{2}=0.69$.

in the chamber. The evaluation with programme 3 shows an overlapping of the temperature ranges of chamber and reference in only $29 \%$ of the record cases and demonstrates the over-temperature of the leaf in the reference to be significantly higher than of that in the chamber.

For the study of the influence of different air flows in the chamber and of artificial ventilation in the reference, different settings of the radial ventilators in chamber and reference were experimented with. Wind velocity in the chambers lies between 1.7 and $2.0 \mathrm{~m} \mathrm{~s}^{-1}$, independent of the settings of the ventilator that are limited by the minimum of air flow necessary for air-conditioning, and the maximum current setting for the ventilator. Probably, in the chamber mainly turbulent flows occur which equilibrate the air-stream conditions. The air velocity in the reference lies between 0.0 and $6.0 \mathrm{~m} \mathrm{~s}^{-1}$.

Figure 3 shows the dependence of the over-temperature due to the incident global radiation in the chamber to be unrelated to the ventilator setting, as explained above. Artificial ventilation in the reference shows the over-temperature to depend to a degree on wind velocity (Fig. 4). Supposing that turbulences prevail 


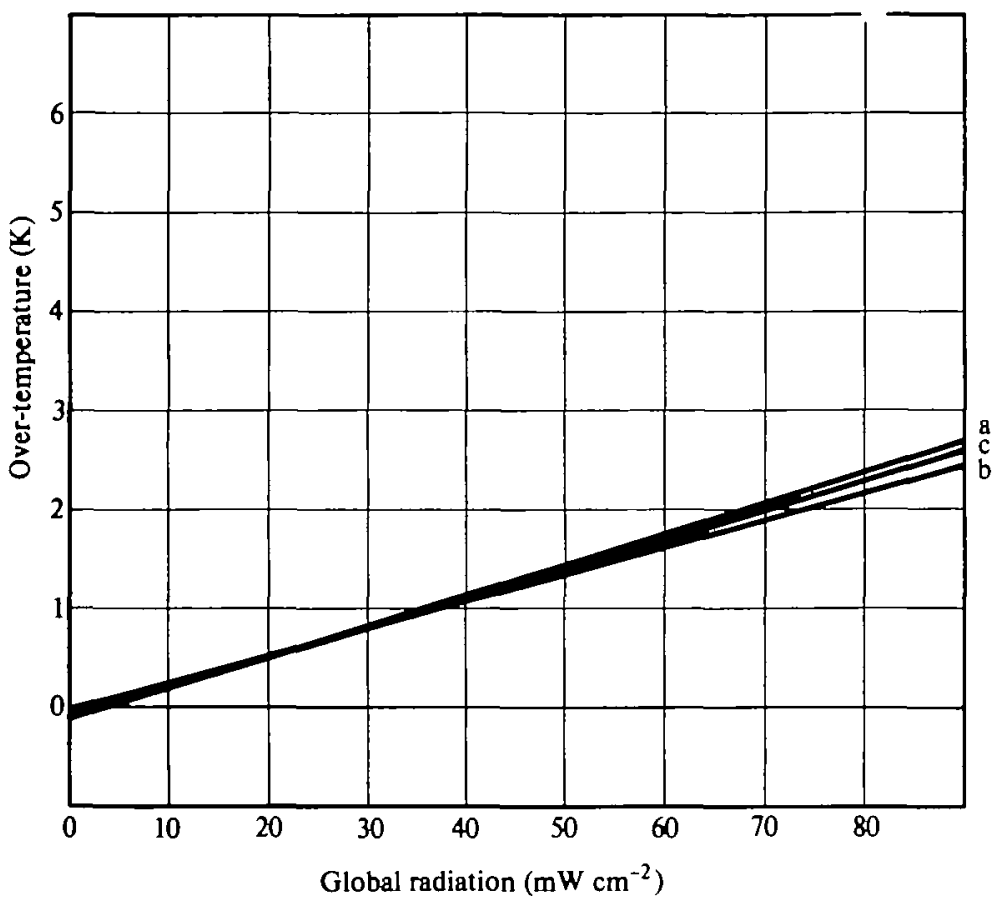

FIG. 3. Global radiation ( $\mathrm{mW} \mathrm{cm}^{-7}$ ) and over-temperature $(\mathrm{K})$ of Nerium oleander L. under various air-flow conditions in the chamber; regression lines for minimum ( $a$ and $b$ ) and maximum (c) setting of the ventilator, and an air-flow between 1.7 and $2.0 \mathrm{~m} \mathrm{~s}^{-1}$.

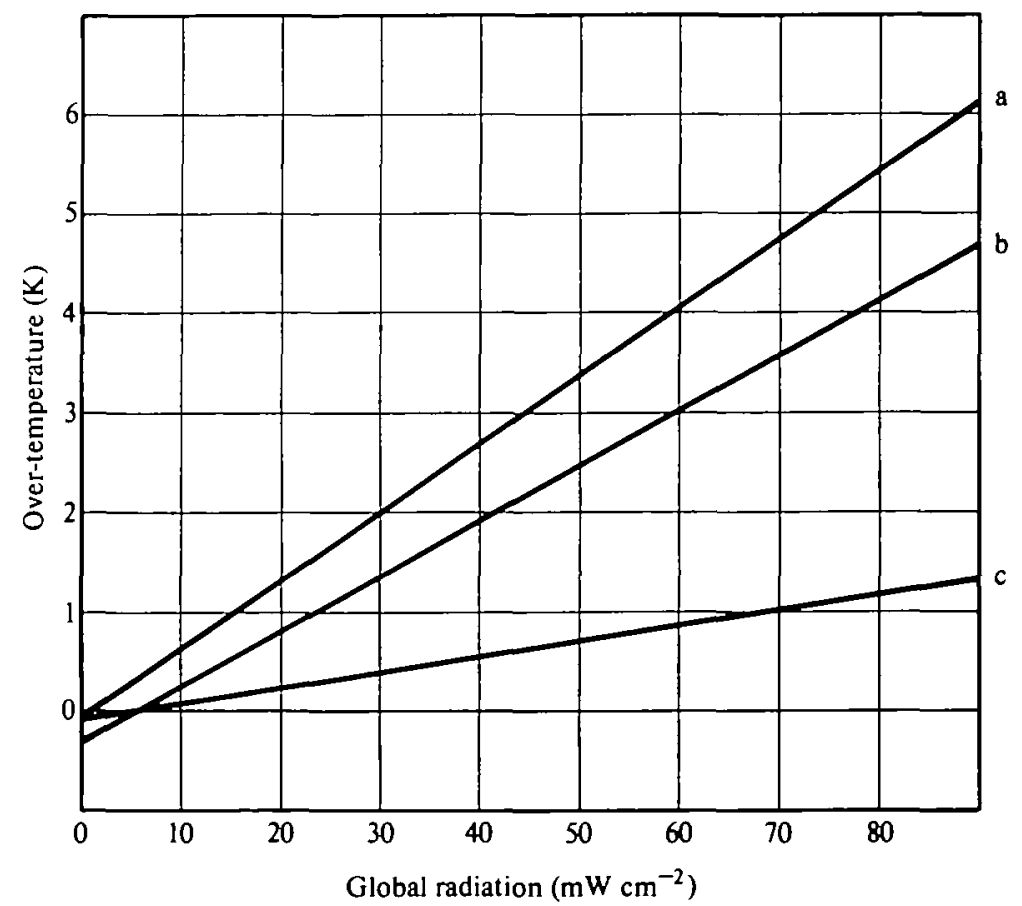

FIO. 4. Global radiation ( $\mathrm{mW} \mathrm{cm}^{-2}$ ) and over-temperatrure $(\mathrm{K})$ of Nerlum oleander L. under various air-flow conditions on the reference. Regression lines for air velocities of (a) 0.0, (b) 1.5 , and (c) $5.8 \mathrm{~m} \mathrm{~s}^{-1}$. 
at the reference leaf, for wind velocities from 1.7 to $2.0 \mathrm{~m} \mathrm{~s}^{-1}$, so that the air-stream quality in chamber and reference is comparable, the radiation dependence of the over-temperature at the reference is about twice as high as that in the chamber.

\section{DISCUSSION}

No error of measurement resulting from radiation influences on the thermocouples could be seen, as could be expected according to available publications. This was in part due to the compensation achieved by measuring the air temperature with thermocouples (Waggoner and Shaw, 1952). But the great differences between leaf temperatures measured with vertical and horizontal insertion, point to a large heat carry-off by the wire material. The measurements of the horizontally inserted thermocouples showed values that were on an average higher by 0.12 to $0.56 \mathrm{~K}$ than the calculated ones of the vertically inserted thermocouples.

The evaluation of the measurements showed that it is essential to eliminate irregularly occurring events when evaluating open-air measurements. It proved to be advantageous to use the values of three thermocouples inserted in the same way, since in the case of the elimination of one value in the validity check there were still two others available.

For laboratory purposes it is sufficient to use only two thermocouples crossing the isotherms in the different ways. For future measurements under field conditions, the use of at least two thermocouples inserted horizontally is advantageous, because unavoidable errors lead to a higher spread of measurement results. The thermocouples used for the air-temperature measurement in chamber and reference showed surprisingly few errors although they were stressed by the air movements.

\section{CONCLUSIONS}

The leaf over-temperatures occurring in air-conditioned gas-exchange chambers whose air-temperature is controlled according to the actual open-air conditions (follow-up control) are lower than those in the open. One reason is the reduced global radiation inside the Plexiglas-taped chamber. This phenomenon is well described both as regards quantity and quality of the incident radiation, by Eller and Koch (1977). The other reason for lower over-temperatures is the air movement inside the chamber that differs basically from open-air conditions. We suspect the existence of mostly turbulent air streams which occur in the open only at much higher wind velocities. The air flow in the ventilated chamber must be analysed before improvements of the chamber system with a view to developing a wind-regulating system according to open-air conditions can be attempted.

\section{ACKNOWLEDGEMENTS}

This work was supported by grants of the Swiss National Science Foundation and the Deutsche Forschungsgemeinschaft. 


\section{LITERATURE CITED}

AVERY, J., 1967. J. exp. Bot. 18, 379-96.

BENECKE, U., 1976. What's New in Forest Res. 43, 4p.

BERGER-LANDEFELDT, U., 1958. Ber. dt. bot. Ges. 71, 21-33.

Bogenrieder, A., and KLEIN, R., 1977. Angew. Bot. 51, 99-107.

Bosian, G., 1933. Z. Bot. 26, 209.

1955. Planta, 45, 470-92.

1960. Flora, 149, 167-88.

Caldwell, M. M., 1972. Int. Symp. USSR Acad. Sci. USSR June 7-19 Pp. 27-29.

Casperson, G., 1957. Z. Bot. 45, 433-73.

DuCHON, C. E., 1964. J. appl. Met. 3, 327-35.

ELLER, B. M., 1971 Energiebilanz und Blattemperatur. Diss. Univ. Zurich.

- and KoCH, W., 1976. EDV in Medizin u. Biol. 7, 81-6.

-_ 1977. Photosynthetica 11, 268-75.

Gates, D. M., 1964. Agron.j. 56, 273-7.

1965. Ecology, 46,1-13.

JARVIS, P. G., and CATSKÝ, J., 1971a. In Plant photosynthetic production. Manual of methods. Eds. Z. Sesták, J. Catský, and P. G. Jarvis. Dr. W. Junk N.V. Publ., The Hague. Pp. 58-9. 1971b. Ibid. Pp. 59-78.

ECKardT, F. E., Koch, W., and Koller, D., 1971a. Ibid. Pp. 78-84.

ECKARDT, F. E., KoCH, W., and Č ATSKÝ, J., 1971b. Ibid. Pp. 84-104.

Koch, W., and Eller, B. M., 1977. Flora, 166, 279-88.

- KLeIN, E., and WALZ, H., 1968. Siemens-Z., 42, 392-404.

- LANGe, O. L., and Schulze, E.-D., 1971. Oecologia, 8, 296-309.

Lange, O. L., and Schulze, E.-D., 1971. In Ecological Studies. Eds. W. D. Billings, F. Golley, O. L. Lange, and J. S. Olson. Vol. 2 (Ed. H. Ellenberg: Integrated Experimental Ecology. Methods and Results of Ecosystem Research in the German Solling Project, 16-28. Springer: Berlin, Heidelberg, New York.

- Schulze, E.-D., Evenari, M., Kappen, L., and Buschвom, U., 1974. Oecologia 17, 97-110.

- 1975. Ibid. 18,45-53.

LoOMIs, W. E., 1965. Ecology, 46, 14-17.

Parlange, J.-Y., and Wagooner, P. E., 1972. Pl. Physiol., Lancaster 50, 60-63.

W AGgoner, P. E., and HeICHEL, G. H., 1971. Ibid., 48, 437-42.

PISEK, A., 1960, In Encyclopedia of plant physiology, Vol. V/2. Ed. W. Ruhland. Springer: Berlin, Heidelberg, New York. Pp. 376-414.

Schulze, E.-D., 1970. Flora, 159, 177-232.

— and KOCH, W., 1971. Proc. Brussels Symp. UNESCO. Pp. 141-57.

LANGE, O. L., and KOCH, W., 1972a. Oecologia, 8, 334-55.

$1972 b$. Ibid. 9, $17-40$.

Schwarz, W., 1969. Proc. 3rd. For. Microclimate Symp. Alberta. Pp. 225-6.

- 1971. Ber. dt. bot. Ges. 84, 585-94.

StẢLfelt, M. G., 1960a. In Encyclopedia of plant physiology, Vol. V/2. Ed. W. Ruhland. Springer; Berlin, Heidelberg, New York. Pp. 100-117.

1960b. Ibid. Pp. 118-122.

WAGgoner, P. E., and ShAw, R. H., 1952. Pl. Physiol., Lancaster, 27, 710-24. 